Published in final edited form as:

World Neurosurg. 2015 July ; 84(1): 22-25. doi:10.1016/j.wneu.2015.05.004.

\title{
Acute Brain Injury after Subarachnoid Hemorrhage
}

\author{
Yusuke Egashira, MD, PhD1, Guohua Xi, MD¹, Neeraj Chaudhary, MBBS ${ }^{2}$, Ya Hua, MD11, and \\ Aditya S. Pandey, MD ${ }^{1}$ \\ ${ }^{1}$ Department of Neurosurgery, University of Michigan, Ann Arbor, Michigan, USA \\ ${ }^{2}$ Department of Radiology, University of Michigan, Ann Arbor, Michigan, USA
}

\begin{abstract}
Keywords
Acute brain injury; animal models; hydrocephalus; magnetic resonance imaging; white matter; subarachnoid hemorrhage
\end{abstract}

\section{BACKGROUND}

Spontaneous subarachnoid hemorrhage (SAH) caused by the rupture of cerebral aneurysms is a subtype of stroke that carries particularly high mortality and morbidity ${ }^{7}$. Immediately after aneurysmal rupture, many physiological derangements, such as elevated intracranial pressure, decreased cerebral blood flow, and global cerebral ischemia, may occur ${ }^{4}$. These immediate responses trigger various cascades of events resulting in pathological changes in the affected brain within the acute phase of SAH. Moreover, excessive amount of extravasated blood and its degradation products are known as the major contributors to brain injury after hemorrhagic stroke. ${ }^{1}$. As yet, the few clinically available treatments for SAH mainly focus on prevention of aneurysmal rebleeding and prophylaxis of delayed cerebral ischemia caused by vasospasm; however, no effective treatments against SAH-induced acute brain injury are available. We briefly describe the recent advances and future direction in the research for SAH-induced acute brain injury.

\section{NEURONAL DEATH}

The leading cause of neuronal death after SAH is transient global ischemia induced by elevation of intracranial pressure. Global ischemia seems to initiate disruption of the BBB as well initiating inflammation which contributes to additional neuronal death. ${ }^{4}$. In addition, excessive iron, the major degradation products of hemoglobin, has been determined as a key factor that causes neuronal death post $\mathrm{SAH}^{6}$. In a rat arterial perforation model, there was excessive accumulation of nonheme iron and iron-handling proteins in tissue adjacent to

\footnotetext{
(C) 2015 Published by Elsevier Inc.

CORRESPONDENCE: Aditya S. Pandey, MD, Department of Neurosurgery, University of Michigan, 1500 E. Medical Center Dr., Room 3552 TC, Ann Arbor, MI 48109-5338, Tel: 734-615-4486; Fax: 734-936-9294, adityap@med.umich.edu.

Publisher's Disclaimer: This is a PDF file of an unedited manuscript that has been accepted for publication. As a service to our customers we are providing this early version of the manuscript. The manuscript will undergo copyediting, typesetting, and review of the resulting proof before it is published in its final citable form. Please note that during the production process errors may be discovered which could affect the content, and all legal disclaimers that apply to the journal pertain.
} 
SAH. High iron content in neurons leads to oxidative DNA injury and results in neuronal death. Iron chelator, deferoxamine, effectively reduced elevations of iron and iron-handling proteins in the brain and has been shown to acute neuronal injury after $\mathrm{SAH}^{6}$. These results suggest that iron and iron-handling proteins are potential therapeutic targets to limit acute brain injury post SAH.

\section{WHITE MATTER INJURY}

It is well known that the components of white matter, axons and myelin-producing oligodendrocytes, are extremely vulnerable to damage in a various neurological diseases ${ }^{2}$. Surprisingly, only few previous reports have focused on white matter injury post SAH. We recently demonstrated the evidence of SAH-induced acute white matter injury in mice. In that report, MRI clearly showed the abnormality along the corpus callosum at 24 hours after SAH induction, and this abnormality correlated with the axonal damage, myelin degradation, and blood-brain barrier (BBB) disruption ${ }^{3}$. It was also demonstrated that ironhandling protein lipocalin 2 depletion attenuated white matter injury after SAH (Figure 1). Lipocalin 2 is known as a mediator of iron uptake, and is implicated in various brain diseases including stroke. These results suggested that lipocalin 2 plays an important role in SAH-induced acute white matter injury. However, the involved mechanisms in this injury, including the detailed role of lipocalin 2, still remain to be elucidated. The mechanistic understanding of white matter injury post SAH could provide therapeutic targets.

\section{ACUTE HYDROCEPHALUS}

Acute hydrocephalus is a common and life-threatening complication after SAH, and has seldom been studied in animal models. Okubo et al. ${ }^{8}$ recently confirmed by MRI that $44 \%$ of animals developed acute hydrocephalus at 24 hours after SAH was induced. The rate of acute hydrocephalus in rats seems to be comparable to that in humans ${ }^{5}$. In humans, poor grade $\mathrm{SAH}$ and the presence of intraventricular hematoma were determined as associated factors for symptomatic hydrocephalus in our large clinical study ${ }^{9}$. Similarly, there was significant correlation between SAH severity and ventricular size in the rat model of SAH. The volume of intraventricular hematoma, ventricular wall damage, and periventricular iron deposition correlated with the development of acute hydrocephalus after SAH (Figure 2). Our EM analyses of rats undergoing SAH show loss of cilia on ependymal surface. Further elucidation of the mechanism of HCP post SAH has the potential of improving clinical outcome as well as preventing shunt dependence and associated complications.

\section{Acknowledgments}

Dr. Guohua Xi was supported by grants NS-073595 and NS-079157 from the National Institutes of Health (NIH). The content is solely the responsibility of the authors and does not necessarily represent the official views of the NIH.

\section{Abbreviations used in this paper}

$\begin{array}{ll}\text { BBB } & \text { blood-brain barrier } \\ \text { MRI } & \text { magnetic resonance imaging }\end{array}$




\section{References}

1. Broderick JP, Brott TG, Duldner JE, Tomsick T, Leach A. Initial and recurrent bleeding are the major causes of death following subarachnoid hemorrhage. Stroke. 1994; 25:1342-1347. [PubMed: 8023347]

2. Dewar D, Underhill SM, Goldberg MP. Oligodendrocytes and ischemic brain injury. J Cereb Blood Flow Metab. 2003; 23:263-274. [PubMed: 12621301]

3. Egashira Y, Hua Y, Keep RF, Xi G. Acute white matter injury after experimental subarachnoid hemorrhage: potential role of lipocalin 2. Stroke. 2014; 45:2141-2143. [PubMed: 24893611]

4. Fujii M, Yan J, Rolland WB, Soejima Y, Caner B, Zhang JH. Early brain injury, an evolving frontier in subarachnoid hemorrhage research. Transl Stroke Res. 2013; 4:432-446. [PubMed: 23894255]

5. Germanwala AV, Huang J, Tamargo RJ. Hydrocephalus after aneurysmal subarachnoid hemorrhage. Neurosurg Clin N Am. 2010; 21:263-270. [PubMed: 20380968]

6. Lee JY, Keep RF, He Y, Sagher O, Hua Y, Xi G. Hemoglobin and iron handling in brain after subarachnoid hemorrhage and the effect of deferoxamine on early brain injury. J Cereb Blood Flow Metab. 2010; 30:1793-1803. [PubMed: 20736956]

7. Nieuwkamp DJ, Setz LE, Algra A, Linn FH, de Rooij NK, Rinkel GJ. Changes in case fatality of aneurysmal subarachnoid haemorrhage over time, according to age, sex, and region: a metaanalysis. Lancet Neurol. 2009; 8:635-642. [PubMed: 19501022]

8. Okubo S, Strahle J, Keep RF, Hua Y, Xi G. Subarachnoid hemorrhage-induced hydrocephalus in rats. Stroke. 2013; 44:547-550. [PubMed: 23212164]

9. Wilson TJ, Stetler WR Jr, Davis MC, Giles DA, Khan A, Chaudhary N, et al. Intraventricular hemorrhage is associated with early hydrocephalus, symptomatic vasospasm, and poor outcome in aneurysmal subarachnoid hemorrhage. J Neurol Surg A Cent Eur Neurosurg. 2015; 76:126-132. [PubMed: 25545809] 
A

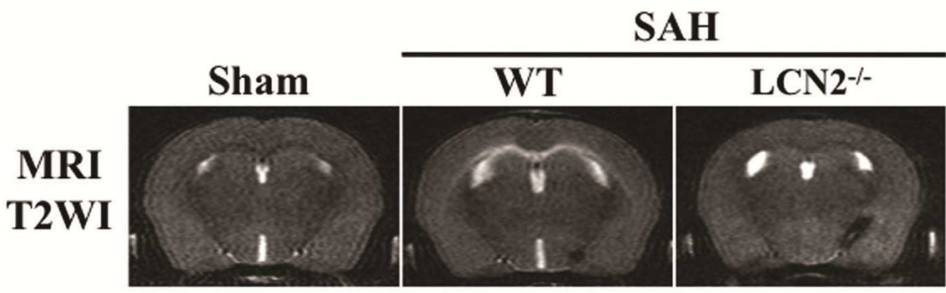

B

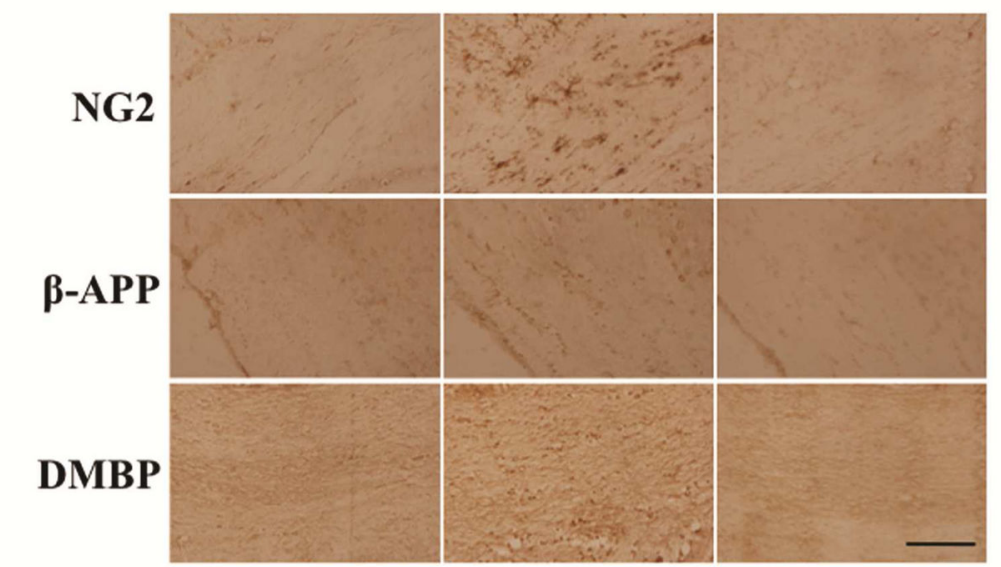

C

NG2
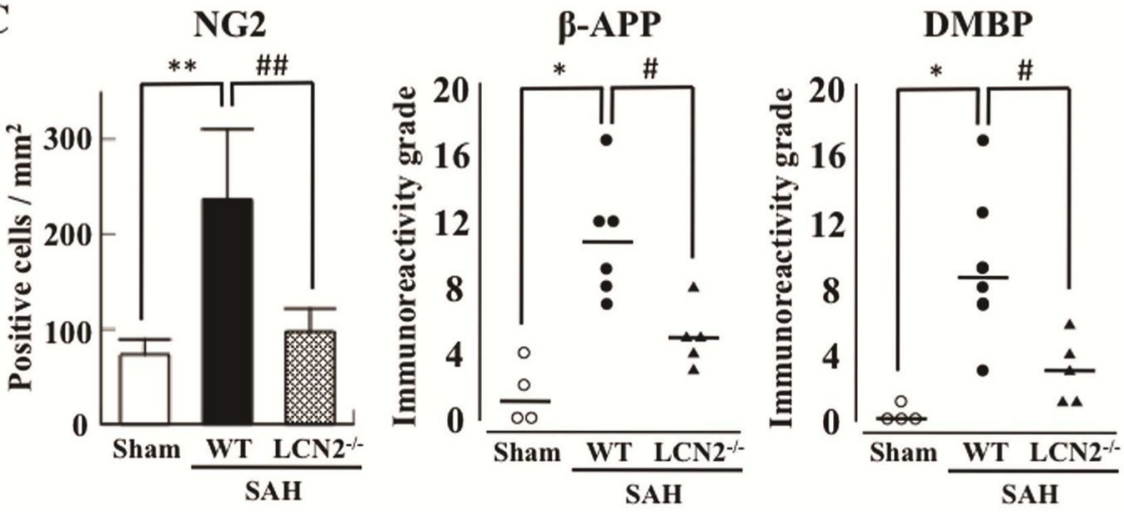

Figure 1.

Representative coronal T2-weighted images (T2WI; A) and NG2 (marker for oligodendrocyte precursors), $\beta$-amyloid precursor protein ( $\beta$-APP; marker for damaged axon) and degraded myelin basic protein (DMBP; marker for degraded myelin) immunohistochemistry in white matter of sham and WT and LCN2 $2^{-/}$animals 24 hours after SAH (B). Quantification of each result. (C). ${ }^{* *} P<0.01,{ }^{*} P<0.05$ vs. WT, and ${ }^{\# \#} P<0.01,{ }^{\#} P<0.05$ vs. $\mathrm{LCN} 2^{-/}$animals. Scale bar $=100 \mu \mathrm{m}$. (Reproduced with permission from: Egashira Y, Hua Y, Keep RF, Xi G: Acute white matter injury after experimental subarachnoid hemorrhage: potential role of lipocalin 2. Stroke 45:2141-2143, 2014.) 
$\mathbf{A}$

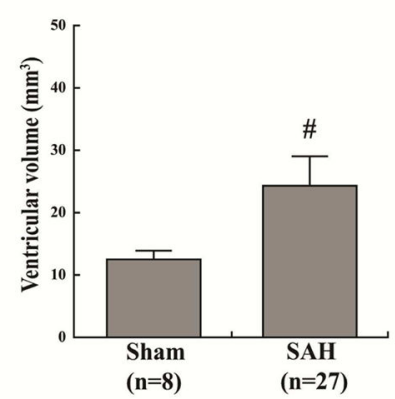

C
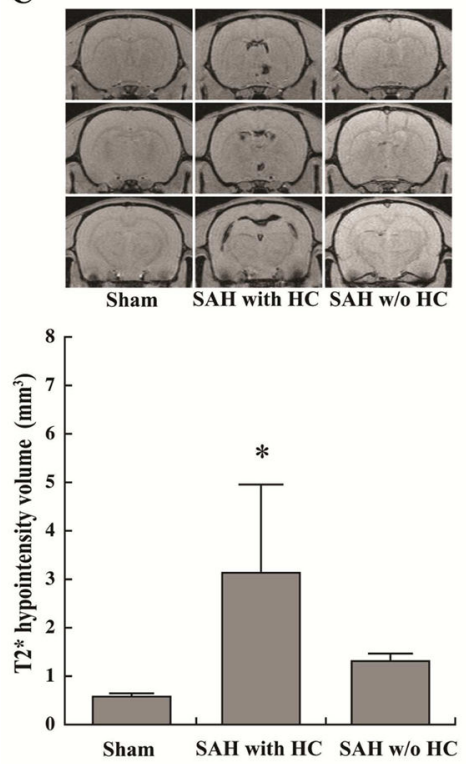

B

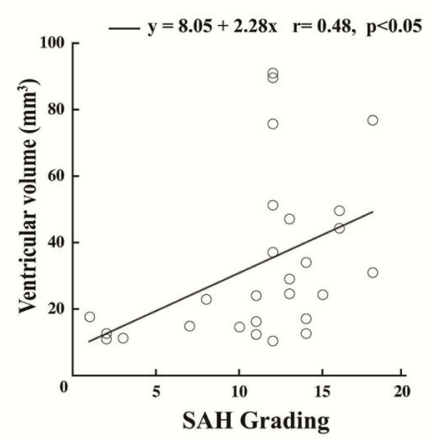

D
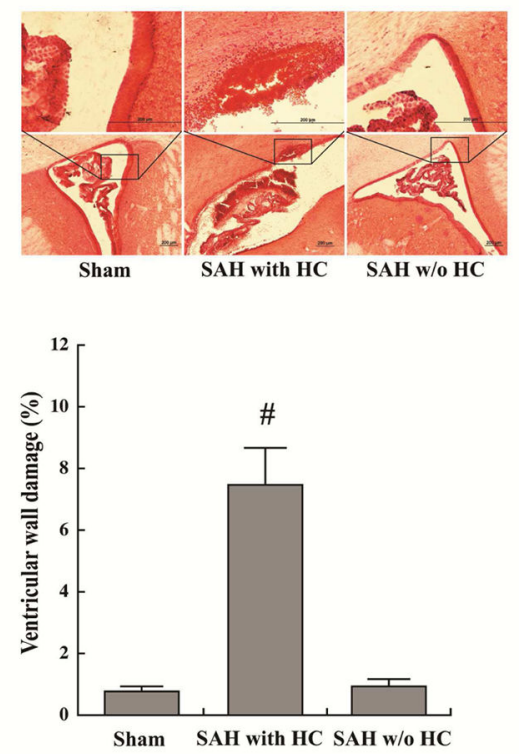

Figure 2.

(A) Ventricular volume 24 hours after endovascular perforation or sham procedure (A). Correlation of ventricular volume and subarachnoid hemorrhage (SAH) grade at 24 hours (B). Coronal T2* images of sham and SAH animals with or without hydrocephalus at 24 hours. Rats with hydrocephalus have a larger hypointensity volume than the sham animals or rats without hydrocephalus (C). Hematoxylin and eosin staining of sham and SAH animals with or without hydrocephalus. Note the presence of intraventricular hemorrhage in the hydrocephalic rat. Boxes show intact ependyma (sham, SAH without hydrocephalus) and disrupted ependyma with intraventricular hemorrhage (SAH with hydrocephalus). SAH animals with hydrocephalus have more ventricular wall damage compared with sham or SAH animals without hydrocephalus (D). $* P<0.05$ and $\# P<0.01$. Scale bar $=100 \mu \mathrm{m}$. (Reproduced with permission from: Okubo S, Strahle J, Hua Y, Keep RF, Xi G: Subarachnoid hemorrhage-induced hydrocephalus in rats. Stroke 44: 547-550, 2013.) 